\title{
Creatinine clearance
}

National Diabetes Information Clearinghouse (NDIC)

\section{Definitions}

Kidney

Defined by National Diabetes Information Clearinghouse (NDIC)

Creatinine

Defined by National Diabetes Information Clearinghouse (NDIC)

\section{Source}

National Diabetes Information Clearinghouse (U.S.). (2009). The diabetes dictionary. [Bethesda, Md.]: U.S. Dept. of Health and Human Services, National Institutes of Health, National Institute of Diabetes and Digestive and Kidney Diseases, National Diabetes Information Clearinghouse.

A test that measures how efficiently the kidneys remove creatinine and other wastes from the blood. Low creatinine clearance indicates impaired kidney function. 